\title{
In vitro recellularization of decellularized bovine carotid arteries using human endothelial colony forming cells
}

Nicolai Seiffert ${ }^{1,2}$, Peter Tang ${ }^{1}$, Eriselda Keshi ${ }^{1}$, Anja Reutzel-Selke' ${ }^{1}$, Simon Moosburner ${ }^{1}$, Hannah Everwien ${ }^{1,3}$, Dag Wulsten ${ }^{3,4}$, Hendrik Napierala ${ }^{1}$, Johann Pratschke ${ }^{1}$, Igor M. Sauer ${ }^{1 *}$ (D, Karl H. Hillebrandt ${ }^{1,5 \dagger}$ and Benjamin Struecker ${ }^{5,6+}$

\begin{abstract}
Background: Many patients suffering from peripheral arterial disease (PAD) are dependent on bypass surgery. However, in some patients no suitable replacements (i.e. autologous or prosthetic bypass grafts) are available. Advances have been made to develop autologous tissue engineered vascular grafts (TEVG) using endothelial colony forming cells (ECFC) obtained by peripheral blood draw in large animal trials. Clinical translation of this technique, however, still requires additional data for usability of isolated ECFC from high cardiovascular risk patients. Bovine carotid arteries (BCA) were decellularized using a combined SDS (sodium dodecyl sulfate) -free mechanicalosmotic-enzymatic-detergent approach to show the feasibility of xenogenous vessel decellularization. Decellularized BCA chips were seeded with human ECFC, isolated from a high cardiovascular risk patient group, suffering from diabetes, hypertension and/or chronic renal failure. ECFC were cultured alone or in coculture with rat or human mesenchymal stromal cells (rMSC/hMSC). Decellularized BCA chips were evaluated for biochemical, histological and mechanical properties. Successful isolation of ECFC and recellularization capabilities were analyzed by histology.

Results: Decellularized BCA showed retained extracellular matrix (ECM) composition and mechanical properties upon cell removal. Isolation of ECFC from the intended target group was successfully performed ( $80 \%$ isolation efficiency). Isolated cells showed a typical ECFC-phenotype. Upon recellularization, co-seeding of patient-isolated ECFC with rMSC/hMSC and further incubation was successful for $14(n=9)$ and $23(n=5)$ days. Reendothelialization (rMSC) and partial reendothelialization (hMSC) was achieved. Seeded cells were CD31 and VWF positive, however, human cells were detectable for up to 14 days in xenogenic cell-culture only. Seeding of ECFC without rMSC was not successful.

\footnotetext{
* Correspondence: igor.sauer@charite.de

${ }^{+}$Karl H. Hillebrandt and Benjamin Struecker contributed equally to this work.

${ }^{1}$ Charité - Universitätsmedizin Berlin, corporate member of Freie Universität Berlin and Humboldt- Universität zu Berlin, Department of Surgery, Campus Charité Mitte | Campus Virchow-Klinikum, Augustenburger Platz 1, 13353

Berlin, Germany

Full list of author information is available at the end of the article
}

(c) The Author(s). 2021 Open Access This article is licensed under a Creative Commons Attribution 4.0 International License, which permits use, sharing, adaptation, distribution and reproduction in any medium or format, as long as you give appropriate credit to the original author(s) and the source, provide a link to the Creative Commons licence, and indicate if changes were made. The images or other third party material in this article are included in the article's Creative Commons licence, unless indicated otherwise in a credit line to the material. If material is not included in the article's Creative Commons licence and your intended use is not permitted by statutory regulation or exceeds the permitted use, you will need to obtain permission directly from the copyright holder. To view a copy of this licence, visit http://creativecommons.org/licenses/by/4.0/ The Creative Commons Public Domain Dedication waiver (http://creativecommons.org/publicdomain/zero/1.0/) applies to the data made available in this article, unless otherwise stated in a credit line to the data. 
(Continued from previous page)

Conclusion: Using our refined decellularization process we generated easily obtainable TEVG with retained ECMand mechanical quality, serving as a platform to develop small-diameter $(<6 \mathrm{~mm}) \mathrm{TEVG}$. ECFC isolation from the cardiovascular risk target group is possible and sufficient. Survival of diabetic ECFC appears to be highly dependent on perivascular support by rMSC/hMSC under static conditions. ECFC survival was limited to 14 days post seeding.

Keywords: Endothelial Colony forming cells (ECFC), Mesenchymal stromal cells (MSC), Tissue engineering, Bovine carotid artery, Decellularization, Recellularization, Target group specific cells / sick cells, Impaired cell function

\section{Background}

Cardiovascular diseases continue to be the leading cause of death in the United States [1]. Peripheral artery disease (PAD), especially in its advanced form critical limb ischemia (CLI), remains a major cause of vascularrelated morbidity and mortality [2] while being a burden clinically and economically to western world healthcare systems [3, 4]. Bypass surgery is one of the most commonly applied surgical treatment of $\operatorname{PAD}$ today $[5,6]$, with patient-derived grafts remaining the gold standard to bypass constricted areas. Unfortunately, up to $30 \%$ of patients suffering from PAD are unable to provide suitable autologous vessel grafts [7, 8]. Synthetic prosthetic grafts may be used as an alternative for large diameter arteries $(>6 \mathrm{~mm})$, however, mechanical mismatch, adverse host response, reduced patency rates and increased susceptibility to infections have impeded clinical applicability, especially for medium or small diameter arteries (inner diameter $\leq 6 \mathrm{~mm}$ ) [8-12]. To address these problems and create viable alternatives, tissue engineered vascular grafts (TEVG) have been developed using self-assembly and biodegradable scaffold techniques of both synthetic and natural origin [13]. While the results seem promising and are pursued up to clinical trials, no widespread clinical application has been established so far $[13,14]$.

Promising, in this context, is the technique of decellularization, whereby all cellular material is removed and the extracellular matrix (ECM) is preserved with favorable mechanical and biochemical properties [13-18]. Decellularized constructs are seen as interesting platforms [19] for cellular repopulation and have been tolerated in xenogeneic applications [20]. Resulting acellular vascular scaffolds from bovine origin have been commercialized and are available for off-the-shelf purchase as alternatives to expanded polytetrafluoroethylene (ePTFE) prostheses for both hemodialysis access and treatment of CLI in cases of infected implantation sites [21, 22]. After cell removal, however, functional endothelium is absent and the underlying vascular ECM is exposed to blood which may cause both early and late graft failure by thrombosis and intimal hyperplasia [23]. As a prevention, reendothelialization should be pursued to mask thrombocyte-activating ECM and to control smooth muscle cell (SMC) proliferation and contractility [24].

Although recellularized grafts using endothelial cells (EC) have shown improved patency (89\% seeded vs. $29 \%$ acellular) [25] and remodeling capacity [20, 26], the isolation of EC is associated with invasive procedures causing donor site complications, providing a low cell yield and may not be feasible for cell isolation due to vessel quality or availability [27, 28]. Endothelial colony forming cells (ECFC) may be isolated by peripheral blood draw and have successfully been expanded to large-scale in vitro experiments [29-31]. Additionally, ECFC seem not only to be able to cover exposed subendothelial ECM but may actually be of a superior thromboprotective and intimal hyperplasia limiting phenotype when exposed to shear stress [32, 33]. Moreover, to support and stabilize ECFC the importance of co-culture with mesenchymal stromal cells (MSC) has been emphasized [29, 34]. Also, MSC have shown to be of immunomodulatory characteristic and used successfully in xenogenic application [35-37].

ECFC have been in the focus of research for years [38]. In most cases umbilical cord blood-derived ECFC and ECFC isolated from young and healthy donors have been used, although an altered function of adult peripheral ECFC has been reported [39]. Additionally, mounting evidence suggests altered function and proliferation rate of ECFC from aging patients with high cardiovascular risk, including diabetes, hypertension and chronic renal disease [40-42]. Scaffold-reendothelialization using patient-derived ECFC has only been researched to cover synthetic vascular scaffolds so far [43-45]. To our knowledge, the suitability of endothelial colony forming cells sourced by peripheral blood draw from cardiovascular risk patients, the intended clinical target group, for reendothelialization of decellularized vascular scaffolds, has not yet been explored. Therefore, this study focused on isolation, expansion and usage of patient-derived ECFC for recellularization purposes while comparing seeding efficiency of ECFC-mono- with ECFC-rMSC and ECFChMSC-coculture approaches on decellularized BCAchips. Healthy rMSC were used due to easy availability and reported low immunogenicity [37]. Furthermore, a refined decellularization strategy was explored. 

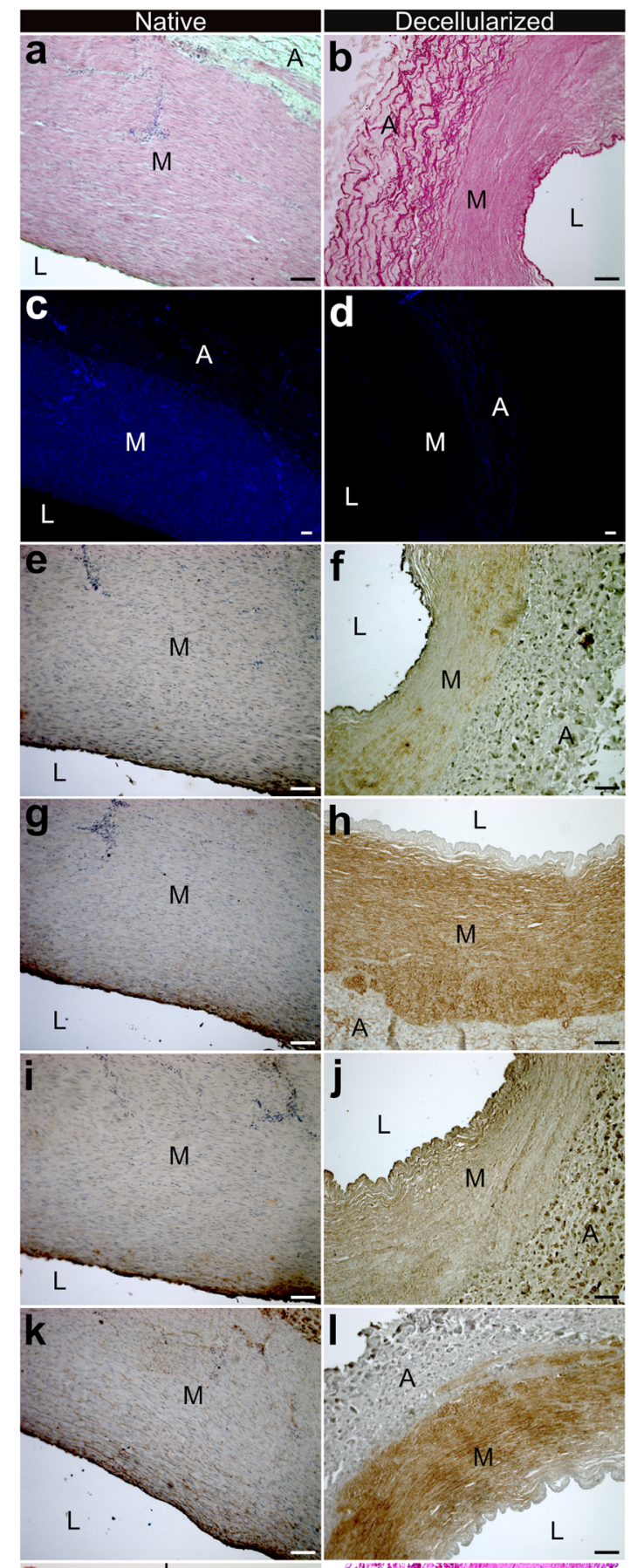

m
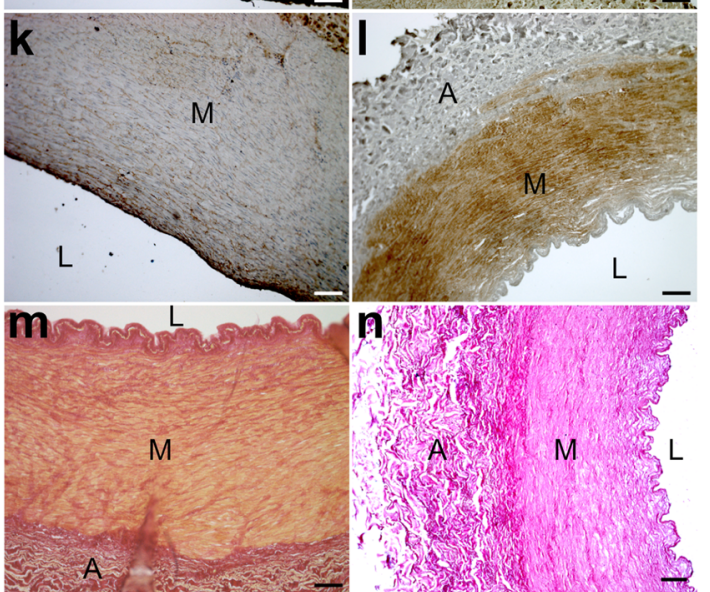

Fig. 1 Native bovine carotid arteries ( $B C A, \mathbf{a}, \mathbf{c}, \mathbf{e}, \mathbf{g}, \mathbf{i}, \mathbf{k}, \mathbf{m})$ were compared to decellularized BCA (b, $\mathbf{d}, \mathbf{f}, \mathbf{h}, \mathbf{j}, \mathbf{l}, \mathbf{n})$. Following decellularization, complete removal of nuclei $(\mathbf{b}, \mathbf{d})$ was observed in $\mathrm{H} / \mathrm{E}-(\mathbf{a}, \mathbf{b})$ and DAPI (c, d) staining. Further histochemical characterization of ECM for collagen I $(\mathbf{e}, \mathbf{f})$, collagen IV $(\mathbf{g}, \mathbf{h})$, fibronectin $(\mathbf{i}, \mathbf{j})$, laminin $(\mathbf{k}, \mathbf{I})$ and Picrosirius red $(\mathbf{m}, \mathbf{n})$ showed successful retention of abundant ECM components. L, M and A indicate lumen, media and adventitia, respectively. Scale bar represents $100 \mu \mathrm{m}$

\section{Results}

\section{Successful decellularization of bovine carotid arterial} grafts

Histological evaluation of decellularized matrices showed complete removal of cellular material throughout the entire vessel wall in H\&E- and DAPI-Staining. While typical arterial wall architecture remained intact, a thinner tunica media and tunica adventitia configuration was observed in decellularized samples (Fig. 1a-d). Immunohistochemical stainings for laminin, fibronectin, collagen-I and collagen-IV in addition to conventional picrosirius red staining were performed to characterize decellularized extracellular matrix and compared to native controls. Microscopic evaluation of ECM showed no loss of abundant ECM components in respective areas of typical appearance, however, the compressed configuration following cell removal resulted in an intensified appearance of ECM-elements, especially in the area of the tunica media (Fig. 1e-l). Picrosirius red staining showed collagen retention after decellularization with removal of cytoplasm (yellow, Fig. 1m, n).

\section{Biochemical analysis of decellularized matrices}

To evaluate content of sulfated glycosaminoglycans (sGAG) during decellularization process, sGAG content was measured in native tissue, after osmotic treatment and after multi-cyclic detergent-enzymatic treatment for up to five cycles (Fig. 2a). An increase of sGAG content was observed during decellularization, reaching a peak after three cycles of detergent-enzymatic treatment at 7.87 median (IQR 0.43$) \mu \mathrm{g} / \mathrm{mg}$ dry weight. This was statistically significant $(p=0.007)$ when compared to native specimens (4.93 IQR $1.61 \mu \mathrm{g} / \mathrm{mg}$ dry weight, Fig. 2a). Further incubation with detergent-enzymatic treatment resulted in reduced sGAG content that reached significance after five consecutive cycles (4.15 IQR $0.90 \mu \mathrm{g} / \mathrm{mg}$ dry weight) when compared to maximum sGAG content after three detergent-enzymatic cycles ( $p=0.0013$, Fig. 2a). Therefore, standard decellularization treatment (SDT) was limited to detergent-enzymatic exposure for three consecutive cycles to prevent sGAG loss. To show effective decellularization, DNA content was measured after SDT and compared to native specimens. DNA content declined significantly during decellularization from 2157.00 (IQR 709.00) ng/mg 

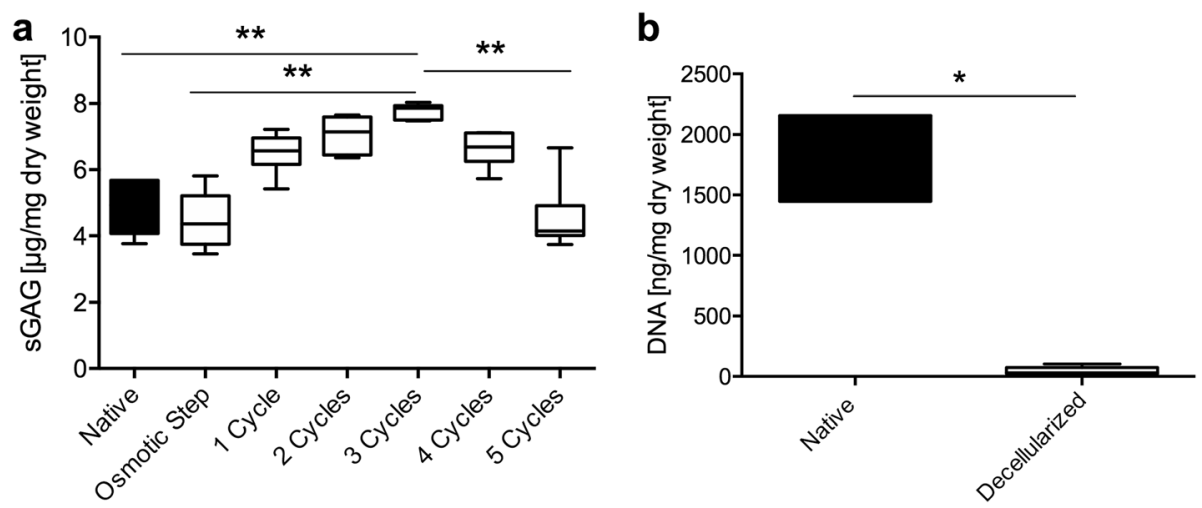

Fig. 2 a The content of sulfated glycosaminoglycans (sGAG) per dry weight increased statistically significant following decellularization treatment after three consecutive detergent-enzymatic treatment cycles. Further incubation for four or five treatment cycles resulted in reduced sGAG content, which reached significance after five cycles. $\mathbf{b}$ DNA amount was reduced significantly after complete standard decellularization treatment (SDT) compared to native controls. ${ }^{*} p<0.05,{ }^{* *} p<0.01$

dry weight in native BCAs to 30.00 (IQR 51.83 ) ng/mg dry weight after SDT (Fig. 2b).

\section{Mechanical properties of decellularized matrices}

To assess mechanical properties altered through the process of decellularization, native specimens $(n=12)$ were compared to samples acquired after freeze-thaw treatment $(n=8)$, SDT $(n=8)$, sterilization $(n=8)$ and SDT without Freeze-Thaw-Treatment $(n=9)$. The time point 'sterilization' represents the final vascular graft to be used for recellularization. SDT without Freeze-Thaw-Treatment is shown only for informatory purposes but was neither sterilized nor used for graft generation. Figure 3 better illustrates the decellularization and sterilization process. All samples were analyzed with regard to Young's Modulus E during low (E ela, Fig. 4a) and high strain (E col., Fig. 4b), point of transition from $\mathrm{E}$ ela to $\mathrm{E}$ col. in regard to stress (Trans stress, Fig. 4c) and strain (Trans strain, Fig. 4d), maximum tolerated stress (Max stress, Fig. 4e) and strain (Max strain, Fig. 4f) and stress (UTC, Fig. 4g) and strain tolerated before rupture (Failure strain, Fig. 4h). Completely decellularized and sterilized samples showed comparable results to native controls by maintaining roughly 91\% of initial stress resilience with regards to Max stress (native 1.23 IQR 0.44 MPa, sterilization 1.11 IQR 0.37 $\mathrm{MPa}, p>1$ ). Similar results were also observed for $\mathrm{E}$ col. (native 2.77 IQR $0.76 \mathrm{MPa}$, sterilization 3.05 IQR 1.61 $\mathrm{MPa}, \mathrm{p}>1$ ), UTS (native 1.06 IQR $0.34 \mathrm{MPa}$, sterilization $0.96 \mathrm{IQR} 0.24 \mathrm{~N}, p>1$ ) and Trans stress (native $0.37 \mathrm{IQR}$ $0.16 \mathrm{MPa}$, sterilization 0.40 IQR $0.13 \mathrm{MPa}, p>1$ ). Further characterization of mechanical behavior of samples acquired throughout the decellularization process revealed differing results. A limited decline of Max stress resilience was recorded after freeze-thaw treatment (1.09 IQR 0.13 $\mathrm{MPa}, 89 \%$ initial stress resilience) which reached statistical significance $(p=0.04)$ after SDT (Max stress 0.80 IQR $0.32 \mathrm{MPa}, 65 \%$ initial stress resilience). Likewise, a decline of $\mathrm{E}$ col. could be seen in samples after freeze-thaw treatment and SDT (Freeze-Thaw-Cycle 2.14 IQR 0.73 MPa, SDT $1.43 \mathrm{IQR} 0.94 \mathrm{MPa}$ ) which was followed by a statistically significant increase $(p=0.04)$ after sterilization (3.05 IQR $1.61 \mathrm{MPa}$ ) compared to SDT but comparable to native specimens. Max strain (native 0.85 IQR 0.37, sterilization 0.53 IQR $0.24 p<0.01$ ), Failure strain (native 1.00 IQR 0.27, sterilization 0.42 IQR $0.27 p=0.01$ ) and Trans strain (native 0.52 IQR 0.25 , sterilization 0.22 IQR $0.23 p=0.03$ ) was reduced up to statistical significance after sterilization but showed no statistically relevant abbreviation to native controls for all other timepoints during graft generation for Max strain (Freeze-Thaw-Cycle 0.89 IQR 0.31, SDT 0.74 IQR 0.22), Failure strain (FreezeThaw-Cycle 0.71 IQR 0.20, SDT 0.70 IQR 0.21) and Trans strain (Freeze-Thaw-Cycle 0.43 IQR 0.14, SDT 0.37 IQR 0.18). While a reduction of UTS was observed for all groups (Freeze-Thaw-Cycle 0.96 IQR 0.29, SDT 0.73 IQR 0.28 ), it did not reach statistical significance. Trans stress did not show any statistically significant changes throughout graft generation process (Trans stress 0.30 IQR 0.19 $\mathrm{MPa}$ ). E ela, however, showed an increase during graft generation that reached statistical significance after sterilization (native $0.31 \mathrm{IQR} 0.34 \mathrm{MPa}$, Freeze-ThawCycle 0.48 IQR $0.49 \mathrm{MPa}$, SDT 0.54 IQR $0.52 \mathrm{MPa}$, sterilization $1.28 \mathrm{IQR} 0.75 \mathrm{MPa} p=0.008$ ). SDT without Freeze-Thaw-Cycle showed significantly altered mechanical test results compared to sterilization (E ela $0.21 \mathrm{IQR}$ $0.17 \mathrm{MPa}, p<0.001$, Trans stress $0.23 \mathrm{IQR} 0.02 \mathrm{MPa}, p=$ 0.016), SDT (E col. $3.12 \mathrm{IQR} 0.40 \mathrm{MPa}, p=0.004$ ) and Freeze-Thaw-Cycle (Trans stress $0.41 \mathrm{IQR} 0.18 \mathrm{MPa}, p=$ 0.049) while alle other measurements remained comparable (UTS $1.00 \mathrm{IQR}$ 0.27 MPa, Failure strain 0.67 IQR 0.15, Trans strain 0.35 IQR 0.13, Max stress 1.09 IQR 


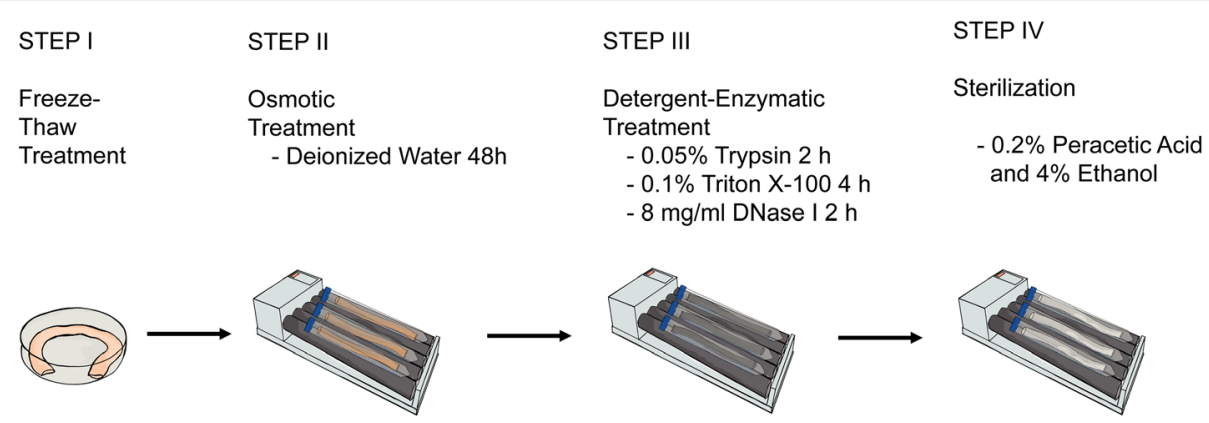

Fig. 3 Graphic display of decellularization process. Decellularization treatment consisted of freeze-thaw treatment, osmotic treatment and multicyclic detergent-enzymatic treatment. To identify necessary cumulative incubation time for cell removal while preserving ECM-components, detergent-enzymatic treatment was performed in cycles, each consisting of trypsin-, Triton X-100- and DNase-treatment. Detergent-enzymatic decellularization cycles were continued for 5 cycles. Analytics showed complete cell removal in histology and significant DNA reduction while preserving SGAG content after three detergent-enzymatic decellularization cycles. SGAG wash out was observed starting at four or more detergent-enzymatic decellularization cycles, therefore standard decellularization treatment (SDT) was defined as freeze-thaw-treatment, osmotic treatment and three consecutive detergent-enzymatic decellularization cycles (cycles 4 and 5 are crossed out in figure). All decellularized specimens were sterilized in peracetic-acid-ethanol-solution prior to recellularization

$0.26 \mathrm{MPa}$, Max strain $0.68 \mathrm{IQR} 0.12$ ). Complete data is available as a supplemental file.

\section{Patient characteristics}

In total, ECFC were isolated from 10 patients in this study (Table 1 ). The patients were equally male (50\%) and female $(50 \%)$, and the median age of patients at the time of ECFC-isolation was 62 years. All patients underwent surgery prior to ECFC-isolation. Oncological, general and endocrinological surgery was performed in 40, 40 and $20 \%$ of the patients, respectively. Most common comorbidities were arterial hypertension (80\%), renal failure (40\%) and diabetes (30\%). None of the patients were active smokers.

\section{Isolation of endothelial colony forming cells}

Cell-Isolation via peripheral blood draw from hospitalized patients was successful in 8 of 10 patients. Cell culture contamination led to the exclusion of two cellisolations, leaving a total of 8 cell-isolations used for further experiments. All included patients were suffering from either diabetes, hypertension, chronic renal failure

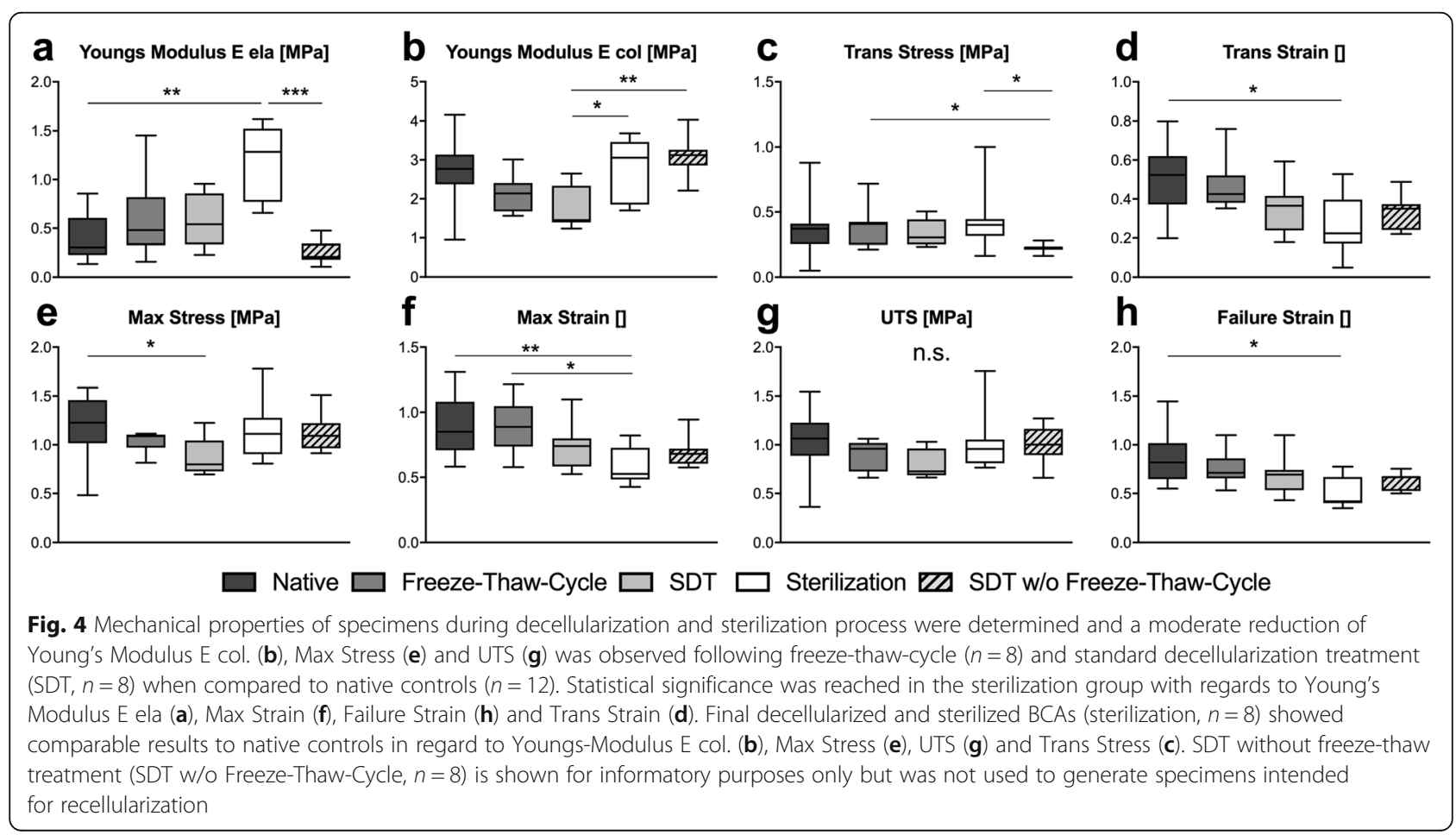


Table 1 Characteristics of donors of endothelial colony forming cells

\begin{tabular}{ll}
\hline Characteristics & $\mathbf{N = 1 0}$ \\
\hline Male sex, \% & 50 \\
Median age at isolation (range), years & 62 (41-83) \\
Non-Smoking, \% & 100 \\
Post-surgical, \% & 100 \\
Co-morbidities, \% & \\
$\quad$ Arterial hypertonia & 80 \\
Diabetes & 30 \\
Renal failure & 40 \\
Coronary heart disease & 10 \\
Admission by surgical departments, \% & \\
Oncological surgery & 40 \\
General surgery & 40 \\
Endocrinological surgery & 20 \\
\hline
\end{tabular}

or a combination thereof (Table 1). Cell cultures were screened daily until cobblestone-like colonies emerged at a mean of 10-12d (Fig. 5). Rapid doubling times followed colony appearance. Acetylated low-density lipoprotein (acLDL) uptake was observed in ECFC cultures incubated with DiI-acLDL by means of colocalization of DAPI- and surrounding DiI-signal (Fig. 5b). Immunofluorescence staining for CD31 (Fig. 5c) and vWF (Fig. 5d) was performed on CytoSpin specimens. Due to the manner of CytoSpin-preparation, no results in regard to cell-cell interaction or cell-colony formation could be obtained. Cells generally appeared dense and layered and stained positive on cell surface area for CD31 or within vesicle-like structures consistent with Weibel-Palade-Bodies for vWF.

\section{Seeding of hECFC on ECM-chips}

Decellularized ECM-chips were seeded with human endothelial colony forming cells (hECFC). Recellularized ECM-chips were examined for cell growth using brightfield and fluorescence microscopy. DAPI- and $\mathrm{H} / \mathrm{E}$-staining of ECM-chips recellularized with hECFC in monoculture for 12 days showed limited to no seeding efficiency. Solitary cells or cell residue on luminal ECM-chip-side could be found in only one of nine recellularized samples $(n=9)$ in $H \& E$ staining (Fig. 6a). We were unable to confirm any cell nuclei in DAPI-staining (Fig. 6b).

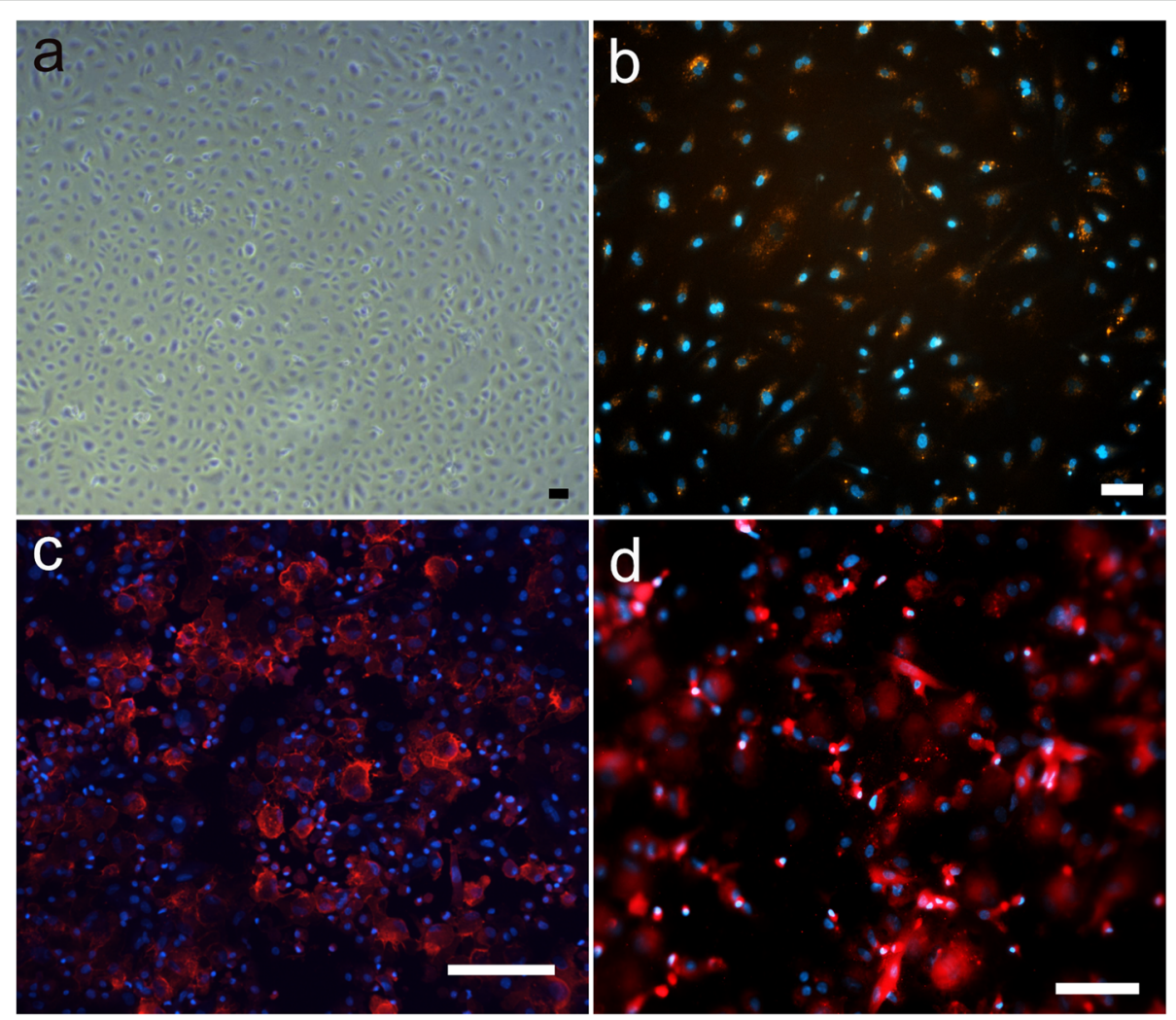

Fig. 5 Inverted brightfield and immunofluorescence microscopy of endothelial colony forming cells (ECFC). Inverted brightfield microscopy showed cobblestone-like appearance (a). Fluorescent microscopic images of ECFC show nuclei in blue (DAPI; $\mathbf{b}, \mathbf{c}, \mathbf{d})$ in colocalization with DilacLDL (orange, b), CD31 (red, c) and von Willebrand factor (red, d). Scale bars represent $100 \mu \mathrm{m}(\mathbf{b}, \mathbf{c}, \mathbf{d})$ or $200 \mu \mathrm{m}(\mathbf{a})$ respectively 


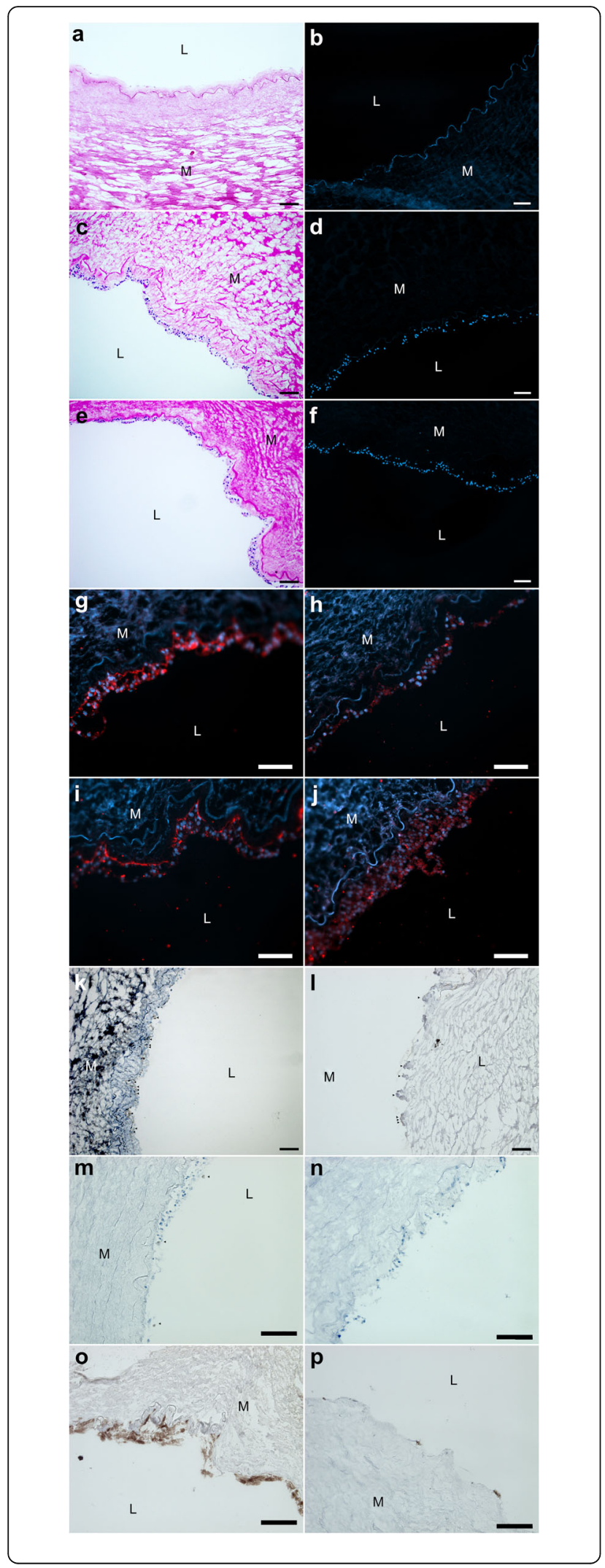

Fig. 6 Inverted brightfield and immunofluorescence microscopy of recellularized extracellular matrix (ECM) chips. ECM-chips were seeded with endothelialcolony forming cells (ECFC) in monoculture $(\mathbf{a}, \mathbf{b})$ or in coculture with rat ( $\mathrm{rMSC}, \mathbf{c}-\mathbf{k}, \mathbf{m}, \mathbf{n})$ or human mesenchymal stromal cells (hMSC, I, o, p) andincubated for 14 (a-d, $\mathbf{g}, \mathbf{h}, \mathbf{m})$ or 23 days $(\mathbf{e}, \mathbf{f}, \mathbf{i}, \mathbf{j}, \mathbf{k}, \mathbf{l}, \mathbf{n}-\mathbf{p})$. H\&E (a, $\mathbf{c}, \mathbf{e})$, DAPI (b, $\mathbf{d}, \mathbf{f})$, $\operatorname{VWF}(\mathbf{g}, \mathbf{i})$ and $\operatorname{CD} 31(\mathbf{h}, \mathbf{j}, \mathbf{o})$ staining revealed confluent cellattachment on luminal ECM-chip side. A trend towards layered cell growth was observed in samples incubated for 23 days $(\mathbf{e}, \mathbf{f}, \mathbf{i}, \mathbf{j})$. CD90 (k, I, arrows),HNA (m, $\mathbf{n}, \mathbf{p})$ staining was observed. Scale bar represents $100 \mu \mathrm{m}$

\section{Seeding of co-cultured hECFC with rMSC on ECM-chips}

Easily available rat mesenchymal stromal cells (rMSC) were used for co-culture applications. Matrices seeded with hECFC in co-culture with rMSC showed confluent cell attachment to luminal ECM-chips on all recellularized samples. Cell growth remained exclusively along the luminal chip side and no infiltration of cells into the tunica media or adventitia was observed. This was true for both $14 \mathrm{~d}(n=8$, Fig. $6 \mathrm{c}-\mathrm{d})$ and $23 \mathrm{~d}(n=5$, Fig. 6e-f) culture periods. Longer incubation times favored layered cell growth, as this was observed in samples incubated for 23 days more frequently and more distinctly than after 14 days of culture. Cell nuclei appeared rounded in both H\&E- and DAPI-staining for all co-culture approaches. To define the cell origin of seeded cells, immunofluorescence staining was performed for CD31 and vWF as well as CD90 and HNA. Impressive colocalized signal of both CD31 and vWF in regard to DAPI-Signal was observed in confluent cell layers (Fig. 6g-j). The positive immunofluorescent signal appeared in the respective cell areas. Notably, subendothelial vWF-signal, consistent with the typical endothelial cell vWF-storage location, was observed in both culture periods. Furthermore, vWF-Signal was intensified after 23 days of culture (Fig. 6g,i). Scattered CD90-positive staining showed presence of MSC after 23 days for co-culture with rat or human MSC (Fig. 6k [rat], Fig. 6m [human], arrows) while negative control showed no positive signal (Suppl.). However, HNA staining indicated that most of CD 31 and VWF-positive cells originated from rMSC. Only a few HNA positive cells could be found after 14 (Fig. 6m) and none after 23 days (Fig. 6n) of culture.

\section{Seeding of co-cultured hECFC with hMSC on ECM-chips}

Human mesenchymal stromal cells (hMSC) were also used for co-culture applications. Matrices seeded with hECFC in co-culture with hMSC showed partially confluent cell attachment to luminal ECM-chips after 23 days of culture (Fig. 6l). Immunohistological staining was performed for CD31 (Fig. 6o) and CD90 (Fig. 6l). Again, CD31 positive staining was observed. CD90positive staining showed presence of hMSC after 23 days 
(Fig. 6l). Few HNA positive cells were found after 23 days of culture (Fig. 6p).

\section{Discussion}

In this study we evaluate the capability of ECFC acquired through peripheral blood draw from hospitalized patients to reendothelialize decellularized $\mathrm{BCA}$ chips when applied in co-culture with rMSC and hMSC. The results may help to better estimate seeding capabilities of ECFC derived from the intended target group for reendothelialization.

Opposite to autologous vessels, TEVG are not a scarce material and could be implanted at an early disease stage. Ideally, artificial surface reaction through current non-biological devices could be avoided and, as a result, TEVG would be implanted in tissue with fewer inflammatory alterations. Constructive remodeling [46] and further improved patency rates could be obtained by this strategy. In order to acquire readily available and therefore transplantable scaffolds for recellularization, discarded BCAs were decellularized using a combination of decellularization techniques for gentle yet effective cell removal. To prevent inferior mechanical properties [47] and reduced recellularization capabilities through known drastic ECM-modification [48] by sodium dodecyl sulphate (SDS), the main reasons for both early and late graft failure, we modified the clinically successfully applied SDS-free protocol by Olausson et al. [49] Also, a SDS-free approach might evade removal and alteration of base membrane proteins and both less confluent and atypical cell growth [50]. Cell lysis was therefore initiated through a freeze-thaw cycle and incubation with deionized water [51]. Further cell lysis and cell debris removal was obtained by a combination of incubation with trypsin, Triton X-100 and DNase. While non-ionic detergent Triton X-100 is known to affect sGAG modification mildly [50] and was used in lower concentrations than comparable protocols $[49,50]$, sGAG content was significantly reduced after five detergent-enzymatic treatment cycles. Successful decellularization through sufficient DNA reduction to $<50 \mathrm{ng} / \mathrm{mg}$ dry weight and absence of cell nuclei in respective histology [51] was achieved after three detergent-enzymatic cycles, a prerequisite to avoid chronic inflammation and allow constructive remodeling when using scaffolds of xenogenic origin [52]. We limited the exposure of specimens accordingly.

Evaluating mechanical properties at defined time points we saw varying mechanical properties throughout our proposed decellularization protocol. An expected but statistically insignificant decline of strength retention and Youngs Modulus E col. following freeze-thaw treatment may be explained by minor ECM disruption of mainly collagen fibers [51]. A preservation of mechanical properties at statistically significant lower values following SDT but mostly comparable results to native controls following additional peracetic acid (PAA) sterilization process was observed. PAA sterilization has been linked with altered mechanical properties due to oxygen free radical reactivity and crosslinking leading to both tissue specific biaxial strength increase (submucosa) and decrease (bladder) [53, 54] but was used as PAA treated ECM showed unaltered or improved reseeding capabilities $[55,56]$ before. Considering preservation of key mechanical components and sGAG content as well as no detectable cell growth beyond the luminal graft side indicating retained ECM characteristics., the proposed decellularization and sterilization process seems to be favorable. In summary the decellularized and sterilized graft, suitable for recellularization, closely mimics native mechanical characteristics while altered mechanical characteristics may be observed during the decellularization process.

While using ECFC obtained from healthy individuals for recellularization approaches has become common practice and is performed successfully, it does not address the goal to develop autologous treatment options for the intended high-risk cardiovascular target group sufficiently. Krawiec et al. [35] were the first to identify and use adipose-derived stromal cells obtained from a cardiovascular risk group as a potential cell source for TEVG generation while expressing the need to evaluate additional cell groups used for tissue engineering. Altered function and reduced ECFC numbers have not only been observed in aging patients, but also in patients suffering from diabetes, hypertension and chronic renal failure, all being risk factors for PAD $[57,58]$ and indicating a key role of ECFC in cardiovascular disease [40-42]. We therefore evaluated both, the isolation and seeding efficiency of ECFC from high-risk donor populations in this study. Our results demonstrate that patient-derived ECFC can be isolated through peripheral blood draw and expanded successfully ex vivo.

To answer the vital question whether patient-derived ECFC may grow on decellularized xenogenic matrices, BCA-chips were recellularized. In contrast to published data stating successful recellularization using healthy ECFC [25, 54-56], decellularized BCA-chips seeded with patient-derived ECFC showed unsatisfactory seeding efficiency. As improved vasculogenic properties of peripheral blood ECFC co-implanted with MSC have been reported, we hypothesized that especially impaired patient-derived ECFC are dependent on perivascular support [29, 59]. ECFC and MSC are known to interact via both, cell-cell-contacts and paracrine mechanisms. We therefore assumed co-implantation could help both cell types to maintain their respective cell function and 
enable remodeling as well as anastomosis healing upon implantation in vivo and exposure to patient-specific serum. Additionally, MSC have shown to be both, immune evasive and immunosuppressive and can therefore create a low inflammatory environment [60], suitable for constructive remodeling [46]. To explore our hypothesis we used both rat bone-marrow MSC (rMSC) due to easy obtainability and reported low immunogenicity [61] as well as human umbilical cord MSC (hMSC). Published research showed both positive and limiting effects in regard to cell proliferation and survival when comparing allogenic and xenogenic co-culture of ECFC and MSC [62-64]. However, so far only a limited amount of data has been collected and may lead to a distortion of the results in both a positive and negative emphasis.

Unexpectedly, by using a xenogenic co-seeding approach we were able to show that while CD31 and vWF expression in EC typical patterns occurred, these cells did not stain positive for HNA. Therefore, rMSC seemed to express both, CD31 and vWF, and outnumbered ECFC after 14 and 23 days of culture. Under static conditions, ECFC did not survive in great numbers but may have rather supported the differentiation of MSC towards endothelial fate. Co-culture of hMSC and ECFC under similar seeding and cell-culture conditions showed inferior partial reendothelialization compared to rMSC co-culture. Differing seeding-efficiency and cellsurvival may be attributed to either heterogeneous ECFC or varying MSC-sources or both. Additionally, different culture-mediums for MSC could have influenced cell behavior. In summary, comparable to unsatisfactory results in regard to seeding capability of ECFC isolated from high-cardiovascular-risk patients reported previously [65], we saw low seeding capability in co-seeding experiments with MSC [29].

Our findings serve as a reminder that sick cells from patients might provide different characteristics from young and healthy cells. So far, we have only seeded ECM-chips in a two-dimensional cell-culture approach of TEVG-chips of only $0.5 \mathrm{~cm}^{2}$. It remains possible that confluent coverage and function of ECFC and MSC will remain intact and show proper function upon exposure to in vivo conditions. Also, regular function of patientderived MSC is still unclear and should be investigated through rigorous functional testing as others have shown intimal hyperplasia leading to graft-failure upon implantation in vivo [66]. While we have shown comparable mechanical attributes for decellularized scaffolds, in depth biomechanical analysis especially for smaller loads without pre-strain and multiple directions are still to be addressed, preferably using direct testing methods to omit overestimating mechanical characteristics [67].

In order to facilitate the translation of our collected data into clinical applications, additional research is required. In a first step the application of our findings should be evaluated to create a bypass graft from both human ECFC and human MSC of reasonable lengths under physiological flow and pressure conditions, possibly using bioreactors. This would also address the vital question if sick human MSC can be as beneficial as healthy rat MSC. This could be addressed in an animalfree cell and culture medium model using realistically achievable cell counts for seeding. To develop a patientderived autologous TEVG, its reendothelialization in cylindrical form, maturation and implantation would be the logical next step.

\section{Conclusion}

In this proof-of-concept study we are the first to show the inability of patient-derived ECFC, isolated from patients who display a corresponding deposition due to their age and cardiovascular risk factors for the development of PAD, to form a confluent endothelial layer on decellularized bovine carotid arteries. Successful endothelialization was achieved upon co-culture of patientderived ECFC with healthy rat MSC and partial endothelialization was observed for the co-culture of patientderived ECFC with healthy human MSC. Under static conditions, MSC formed a confluent cell layer while expressing typical endothelial cell markers. Furthermore, we show a refined decellularization strategy for widely available BCAs to retain key mechanic and ECM characteristics through an SDS-free approach to be used as small-diameter bypass for patients with PAD.

\section{Methods}

All methods were carried out in accordance with relevant guidelines and regulations. Special permission was obtained for all experimental procedures with local committees and institutions where applicable.

\section{Vessel harvesting}

BCAs were obtained from a slaughterhouse and transported in cooled phosphate buffered saline (PBS) pH 7.4 (PBS, Biochrom, Berlin, Germany) to the laboratory facilities of the Department of Surgery, where surplus tissue was removed. Vessels were washed with PBS and stored frozen at $-80^{\circ} \mathrm{C}$ until further use.

\section{Preparation of Acellular matrices}

The standard decellularization treatment (SDT) consisted of three steps as visualized in Fig. 1:

Step 1 Freeze-Thaw-Treatment: BCA were frozen at $80^{\circ} \mathrm{C}$ for $>24 \mathrm{~h}$ and then thawed to $5^{\circ} \mathrm{C}$.

Step 2 Osmotic Treatment: BCA were rinsed with deionized water for $48 \mathrm{~h}$ on an elliptical tube roller 
mixer (RM 5, Glaswarenfabrik Karl Hecht, Sondheim, Germany).

Step 3 Multi-Cyclic Detergent-Enzymatic Treatment: Multi-cyclic detergent-enzymatic treatment was performed daily for three consecutive days on a roller mixer at $37^{\circ} \mathrm{C}$. BCA were treated each day with $0.05 \%$ Trypsin (Sigma-Aldrich, St. Louis, MO, USA) for $2 \mathrm{~h}$, $0.1 \%$ Triton-X 100 (Roth, Karlsruhe, Germany) for $4 \mathrm{~h}$, both diluted in $0.05 \%$ EGTA (Sigma-Aldrich), and 8 $\mathrm{mg} / \mathrm{mL}$ DNase-I (Roche Diagnostics, Risch, Switzerland) for $2 \mathrm{~h}$. DNase-I was dissolved in DNase reaction buffer containing $10 \mathrm{mM}$ Tris- $\mathrm{HCl}, 2.5 \mathrm{mM}$ $\mathrm{MgCl} 2$ and $0.5 \mathrm{mM} \mathrm{CaCl} 2$ at $\mathrm{pH} 7.6$ at room temperature (RT). Vessels were washed with PBS between treatment-steps. BCAs were stored in PBS solution containing 1\% Penicillin/Streptomycin (Biochrom) at $5{ }^{\circ} \mathrm{C}$. Step 3 was prolonged to 5 days to evaluate sGAG content.

\section{Biochemical analysis of Acellular matrices}

Tissue samples of native and decellularized BCA were homogenized and lyophilized. For all biochemical analysis, processed specimens were compared to native controls using $10 \mathrm{mg}$ dry weight samples.

\section{sGAG-content of Acellular matrices}

Sulfated glycosaminoglycans (sGAG) content was measured following osmotic treatment and after each Multi-Cyclic Detergent-Enzymatic Treatment for 5 days using the previously published protocol by Farndale et al. [68] Native and decellularized tissue samples as well as Chondroitin-4-Sulphate $(0-200 \mu \mathrm{g} / \mathrm{mL}$, Roth) to acquire a standard curve, were incubated in papain-containing-buffer, mixed with 1,9-Dimethylmethylene blue (DMMB) at equal parts and measured at a wavelength of $525 \mathrm{~nm}$ using the NanoDrop 2000C spectrophotometer (Thermo Fisher Scientific, Waltham, MA, USA).

\section{DNA-content of Acellular matrices}

DNA-Content was obtained using DNeasy Blood \& Tissue Kit (Qiagen, Venlo, Netherlands) according to the manufacturer's instructions. Samples were measured using the NanoDrop 2000C.

\section{Mechanical analysis of Acellular matrices}

Acellular Matrices were cut into $5 \mathrm{~mm}$ wide rings with $5 \mathrm{~mm}$ diameters. The thickness was measured while using a digital gage (accuracy: $\pm 0.1 \mathrm{~mm}$; Mitutoyo, Andover, UK). Subsequently the ring specimens were mounted on two custom made wire hooks and finally subjected to low strain rate uniaxial tensile loading to failure testing by means of an Bose tensile machine device (BOSE ElectroForce LM1, Bose
Corporation, Eden Prairie, MN, USA). Specimens were manually prestrained up to approximately $1 \mathrm{~N}$ and subsequently loaded until failure at $0.166 \mathrm{~mm} / \mathrm{s}$, while applied force and displacement was acquired at a $100 \mathrm{~Hz}$ sample rate. Further data analysis was executed using a routine written in MATLAB (The MathWorks, Inc., Natick, MA, USA) converting force $(\mathrm{F}, \mathrm{N})$ and displacement $(\mathrm{d}, \mathrm{mm})$ to engineering stress $(\sigma, \mathrm{MPa})$ and strain $(\varepsilon$, adimensional). The stressstrain curve of each sample was plotted, and the following parameters were calculated: elastic phase modulus (E ela, $\mathrm{MPa}$ ) and collagen phase modulus (E col., MPa), representing Young's modulus under low and high strain determined as linear part of the stress-strain-curve, respectively. Ultimate tensile strength (UTS, MPa), indicating at which stage the sample failed and the corresponding stress-straincurve exhibits the first drop in load, furthermore the maximal stress (Max stress, MPa) as the highest stress experienced. Max strain, Failure strain and Trans strain are defined accordingly (adimensional). Finally, the point at which the slope of E ela and E col. meet (see Suppl.) defines Trans strain and the corresponding point on the stress-strain-curve provides Transition stress (MPa). Native $(n=12)$ and specimens having undergone freeze-thaw-Ttreatment, SDT and sterilization ( $n=8$ each) as well as SDT without freeze-thaw-treetment $(n=9)$ were compared.

\section{Histological analysis of Acellular matrices}

Native vessels and decellularized samples were fixed with 4\% paraformaldehyde (PFA, Roth), dehydrated, paraffinized and cut into $7 \mu \mathrm{m}$ thick sections. Sections were stained with hematoxylin (ITW Reagents, Darmstadt, Germany) and eosin (Morphisto, Frankfurt a.M., Germany) or DAPI (Sigma-Aldrich) to verify the absence of cellular elements and DNA residue. Immunohistochemical stainings for Laminin, Fibronectin, Collagen-I and Collagen-IV as well as conventional picrosirius red staining for collagen were performed to evaluate extracellular matrix components. Table 2 states primary and secondary antibodies used for histological analysis. Following deparaffinization and rehydration, all immunohistochemical samples underwent 3\% peroxidase block and $0.1 \mathrm{M}$ citrate buffer $\mathrm{pH} 6$ antigen retrieval. Respective primary antibodies for fibronectin and collagen I staining were incubated for $2 \mathrm{~h}$ at $37^{\circ} \mathrm{C}$. Designated samples for laminin and collagen IV staining were blocked with $3 \%$ goat serum and incubated with primary $(1 \mathrm{~h})$ and secondary antibody (30 min, goat-anti-rabbit, ab6721, abcam) at $37^{\circ} \mathrm{C}$. All remaining steps were performed using LSAB2 Kit (K0675, Agilent Technologies, Santa Clara, CA, USA). 
Table 2 Overview of antibodies used

\begin{tabular}{lllll}
\hline Target & Host & Dilution & Cat.-No. & Manufacturer \\
\hline $\begin{array}{l}\text { Primary Antibodies } \\
\text { Collagen-I }\end{array}$ & Mouse & $1: 400$ & & H00001278-M03 \\
Collagen-IV & Rabbit & $1: 400$ & Ab6586 & Abnova, Taipei, Taiwan \\
Fibronectin & Rabbit & $1: 400$ & Ab23751 & abcam, Cambridge, UK \\
Laminin & Rabbit & $1: 50$ & Ab11575 Cambridge, UK \\
VWF & Rabbit & $1: 400$ & Ab6994 & abcam, Cambridge, UK \\
CD31 & Rabbit & $1: 100$ & Bs-0195R & abcam, Cambridge, UK \\
CD90 & Rabbit & $1: 10$ & Ab92574 & Bioss Antibodies Inc. Woburn, USA \\
HNA & Mouse & $1: 200$ & Ab191181 & abcam, Cambridge, UK \\
Secondary Antibodies & & & abcam, Cambridge, UK \\
Rabbit & Goat & $1: 400$ & Ab6721 & abcam, Cambridge, UK \\
Mouse & Donkey & $1: 400$ & $715-035-150$ & Dianova, Hamburg, Germany \\
Rabbit & Goat & $1: 400$ & Ab150080 & abcam, Cambridge, UK \\
\hline
\end{tabular}

Isolation of Endothelial Colony Forming Cells (ECFC)

ECFC were isolated similarly to previously published protocols $[69,70]$. Following approval of the ethics committee of the Charité - Universitätsmedizin Berlin (EA1/ 256/14) and in accordance with the declaration of Helsinki, peripheral blood was obtained from hospitalized patients after informed consent. Blood samples were heparinized and treated separately for each patient. Mononuclear cells were isolated using Biocoll (Biochrom) density gradient centrifugation. Mononuclear cell suspension was subsequently plated on fibronectingelatin-coating (Fibronectin $0.005 \mathrm{mg} / \mathrm{ml}$, Merck; Gelatin $0.2 \mathrm{mg} / \mathrm{ml}$, Sigma-Aldrich) and incubated at $37^{\circ} \mathrm{C}$ and $5 \% \mathrm{CO}_{2}$ for 4 days with EBM-2 medium (Lonza, Basel, Switzerland) supplemented with EGM-2 SingleQuots (Lonza), 18\% Fetal Bovine Serum (FBS, Merck) and 1\% Penicillin-Streptomycin (P/S, EGM-2) to reach a final concentration of $20 \% \mathrm{FBS}$ in EGM-2.). Afterwards, all non-adherent cells were washed off with PBS, new EGM-2 medium was added, changed daily for 1 week and then every other day. ECFC were expanded by replating at $80-90 \%$ confluence.

\section{Characterization of isolated ECFC}

Cell cultures were assessed daily for cell growth, colony formation and absence of contamination with an Axiovert 40 CFL microscope (Carl Zeiss AG, Oberkochen, Germany). Isolated ECFC were fixated on microscope slides using the Cytospin (Cytospin 4, Thermo Fisher Scientific) procedure: Cells were trypsinized, aliquoted, centrifuged onto slides and fixated with Merckofix (Merck). Slides were then washed, incubated with protein block (Agilent Technologies) for 45 min (CD31) or PBS containing $1 \%$ bovine serum albumin (BSA, Agilent Technologies) and 0.2\% Triton
X-100 for $10 \mathrm{~min}$ (vWF) at RT. Antibodies were diluted in PBS containing $1 \%$ BSA and $1 \%$ goat serum. Samples were incubated with primary antibodies for $1 \mathrm{~h}$ at $37^{\circ} \mathrm{C}(\mathrm{CD} 31)$ or overnight at $4{ }^{\circ} \mathrm{C}$ (vWF) before being incubated with the secondary antibody for $45 \mathrm{~min}$ at $37^{\circ} \mathrm{C}$. Afterwards, the cells were washed, counterstained with DAPI and mounted with Aquatex (Merck). Isolated ECFC were incubated with EGM-2 Medium containing $10 \mu \mathrm{g}$ DiI-ac-LDL (Merck) for $4 \mathrm{~h}$ at $37^{\circ} \mathrm{C}$ and $5 \% \mathrm{CO}_{2}$. The cells were then washed, counterstained with DAPI, fixated with 4\% PFA and microscopically assessed.

\section{rMSC isolation}

Rat mesenchymal stromal cells (rMSC) were isolated from rat femur bone marrow according to a modified protocol after Soleimani and Nadri [71]. Bones serving as cell sources for rMSC Isolation had been discarded hind limbs from other animal experiments. All initial animal work was performed in accordance with local law and approved by the State Office of Health and Local Affairs (Landesamt für Gesundheit und Soziales, LAGeSo, Berlin, Germany; Reg. No. T 0139/13, T 0301/ 17 and $O$ 0365/11). Briefly, following femur explantation, bones were sterilized in 70\% Ethanol and manually snapped in half under sterile conditions. The intramedullary canal was rinsed with RPMI-Medium (ThermoFischer Scientific) supplemented with 10\% FCS and 1\% $\mathrm{P} / \mathrm{S}$, (RPMI), the cell-containing medium was transferred to a cell culture flask (Corning Inc.) and incubated at $37^{\circ} \mathrm{C} 5 \% \mathrm{CO}_{2}$. After 4 days, the cell culture flasks were rinsed, inspected for adherent cells and fresh RPMI medium was added. rMSC were replated at $70 \%$ confluence. 
Recellularization of acellular BCA matrices with $\mathrm{hECFC}$ or hECFC in coculture with rMSC or hMSC

All steps were performed under sterile conditions. Decellularized matrices were sterilized by incubation for $6 \mathrm{~h}$ with $0.2 \%$ Peracetic Acid (PAA) and 4\% Ethanol (EtOH) followed by washing steps in sterile PBS until the $\mathrm{pH}$ was neutralized. The matrices were then cut to $0.5 \mathrm{~cm}^{2}$ pieces and equilibrated in EGM-2 in 12-well plates overnight.

ECFC derived from high cardiovascular risk donors were used for all recellularization experiments. Expanded hECFC were trypsinized, washed and resuspended in EGM-2 before seeding on the luminal side of matrices in $80 \mu \mathrm{l}$ EGM2 containing $3.6 \times 10^{5} \mathrm{hECFC}$. Seeding medium consisting of equal parts of EGM-2 medium and M-199 medium (rMSC) containing 10\% FBS and 1\% P/S (seeding medium) or ATCC PCS-500-030 Medium supplemented with ATCC PCS-500-040 (hMSC) was prepared. Expanded hECFC and rMSC or human MSC (hMSC, human umbilical cordderived mesenchymal stem cells, ATCC) were trypsinized, washed and resuspended in seeding medium. Approximately $80 \mu \mathrm{l}$ of cell suspension containing $5.5 \times 10^{5}$ ECFC and $4.2 \times 10^{4}$ rMSC or hMSC was added to the luminal side of each matrix followed by $1 \mathrm{~h}$ incubation at $37^{\circ} \mathrm{C} 5 \%$ $\mathrm{CO}_{2}$. Subsequently, $4 \mathrm{~mL}$ of seeding medium was added and seeded matrices were incubated for $72 \mathrm{~h}$ at $37^{\circ} \mathrm{C}$ and $5 \% \mathrm{CO}_{2}$. After $72 \mathrm{~h}$ matrices were transferred carefully to new 12 well plates. Incubation continued for $12(n=8)$ days in monoculture and $14(n=6)$ or 23 (rat $(n=5)$ or human $(n=6)$ MSC) days in co-culture experiments.

\section{Analysis of Recellularized matrices}

Native vessels and recellularized samples were embedded in Tissue Freezing Medium (Leica), snap-frozen and stored at $-80^{\circ} \mathrm{C}$. Cryostat sections $(7 \mu \mathrm{m}$, Thermo Fisher Scientific) were prepared, fixated in cold acetone (Roth), airdried and washed with PBS. Sections were stained with H\&E and DAPI. To prove endothelial origin, CD31- and vWF-staining was performed. Following incubation in boiling $0.01 \mathrm{M}$ Target Retrieval Solution pH 6 (Agilent Technologies) for $20 \mathrm{~min}$, specimens were treated with blocking buffer containing $3 \%$ goat serum and $0.3 \%$ Triton X-100 for $45 \mathrm{~min}$ at RT. Antibodies were diluted in buffer containing $1 \%$ BSA, $1 \%$ goat serum and $0.3 \%$ Triton X-100. Primary antibodies were then applied to tissue samples and incubated at $4{ }^{\circ} \mathrm{C}$ overnight. The secondary antibody (1:400, ab150080, abcam) was applied to tissue samples following washing for $45 \mathrm{~min}$ at $37^{\circ} \mathrm{C}$. Specimens were then washed, counterstained with DAPI and coverslipped using Aquatex (Sigma-Aldrich). To show cell distribution of human- and MSC-origin CD90 and human nuclear antigen (HNA) histochemical staining was performed. Epitope retrieval by using the pressure cooker method for $5 \mathrm{~min}$ while specimens were placed in boiling TRIS/EDTA-buffer and peroxidase blocking was performed for CD90 staining. Blocking was performed using protein block for HNA. Primary antibody $(1: 20$, ab92574; 1:200, ab191181) was then applied and incubated over night at room-temperature. The secondary antibody (1:400, ab6721; 1:400, 715-035150) was applied to tissue samples following washing for $45 \mathrm{~min}$ at $37^{\circ} \mathrm{C}$ (CD90) or $30 \mathrm{~min}$ at RT (HNA). All remaining steps were performed using LSAB2 Kit (K0675, Agilent Technologies, Santa Clara, CA, USA). Microscopic evaluation was performed using Observer Z1 microscope (Carl Zeiss AG) or EVOS FL Auto microscope (ThermoFisher Scientific, Fig. 5c).

\section{Statistical analysis}

All calculations were performed using GraphPad Prism version 6.04 for Mac, GraphPad Software, La Jolla, CA, USA. Data was tested for normality using Shapiro-Wilk test. Statistical comparison was performed by either Friedman test (sGAG-content), Wilcoxon test (DNAcontent) or Kruskal-Wallis test (mechanical data). Data is presented as median and interquartile range (IQR). $p$ Values below 0.05 were considered statistically significant. All graphs in this study show medians with the respective IQR.

\section{Supplementary Information}

The online version contains supplementary material available at https://doi. org/10.1186/s13036-021-00266-5.

Additional file 1. Shows complete data of the mechanical experiment including stress-strain curves and negative control images for histological staining.

\section{Authors' contributions}

NS developed the project idea, performed the experiments and wrote the manuscript. PT helped during all parts of the project. EK helped with the analysis of the experiments including histology. ARS discussed results with us and performed the statistical evaluation. SM helped with the analysis of the experiments and statistical analysis. HN helped develop the project idea and helped with the analysis of the experiments. HE helped establish the decellularization technique and with the analysis of the experiments. DW helped with the mechanical analysis. JP discussed the results and proofread the manuscript. IMS developed the project idea, discussed the results and proofread the manuscript. KH developed the project idea, supervised the revision, helped with the analysis of the experiments and proofread the manuscript. BS developed the project idea, supervised the whole project and proofread the manuscript. The author(s) read and approved the final manuscript.

\section{Funding}

This work was supported by the BMWi (Bundesministerium für Wirtschaft und Energie) project KF2852504CS4. Dr. Hillebrandt is a participant in the $B / H$ Charité Junior Clinician Scientist Program funded by the Charité -

Universitätsmedizin Berlin and the Berlin Institute of Health. Priv.-Doz. Dr. Struecker was participant in the BIH Charité Clinician Scientist Program funded by the Charité - Universitätsmedizin Berlin and the Berlin Institute of Health. Hannah Everwien was participant in the BIH Medical Doctoral Research Stipends funded by the Charité - Universitätsmedizin Berlin and the Berlin Institute of Health. Funding did not influence the design of the study and collection of data, analysis, and interpretation of data and in writing the manuscript. Open Access funding enabled and organized by Projekt DEAL. 


\section{Availability of data and materials}

The datasets used and/or analyzed during the current study are available from the corresponding author on reasonable request.

\section{Declarations}

\section{Ethics approval and consent to participate}

Approval of the ethics commission of the Charite - Universitätsmedizin Berlin (EA1/256/14) was obtained for this study. All included patients provided written informed consent.

\section{Consent for publication}

Not applicable.

\section{Competing interests}

The authors declare no competing financial interests.

\begin{abstract}
Author details
${ }^{1}$ Charité - Universitätsmedizin Berlin, corporate member of Freie Universität Berlin and Humboldt- Universität zu Berlin, Department of Surgery, Campus Charité Mitte | Campus Virchow-Klinikum, Augustenburger Platz 1, 13353 Berlin, Germany. ${ }^{2}$ Department for Trauma and Orthopedic Surgery, Vivantes-Hospital Spandau, Berlin, Germany. ${ }^{3}$ Berlin Institute of Health at Charité - Universitätsmedizin Berlin, Charitéplatz 1, 10117 Berlin, Germany. ${ }^{4}$ Charité - Universitätsmedizin Berlin, corporate member of Freie Universität Berlin and Humboldt- Universität zu Berlin, Julius Wolff Institute, Augustenburger Platz 1, 13353 Berlin, Germany. ${ }^{5}$ Berlin Institute of Health at Charité - Universitätsmedizin Berlin, BIH Academy, Clinician Scientist Program, Charitéplatz 1, 10117 Berlin, Germany. ${ }^{6}$ Department of General, Visceral and Transplant Surgery, University Hospital Münster, Münster, Germany.
\end{abstract}

Received: 17 October 2020 Accepted: 7 April 2021

Published online: 21 April 2021

\section{References}

1. Benjamin EJ, Virani SS, Callaway CW, Chamberlain AM, Chang AR, Cheng S, et al. Heart disease and stroke Statistics-2018 update: a report from the American Heart Association. Circulation. 2018;137(12):e67-492. https://doi. org/10.1161/CIR.0000000000000558.

2. Agarwal S, Pitcavage JM, Sud K, Thakkar B. Burden of readmissions among patients with critical limb ischemia. J Am Coll Cardiol. 2017;69(15):1897-908. https://doi.org/10.1016/j.jacc.2017.02.040.

3. Arruda-Olson AM, Moussa Pacha H, Afzal N, Abram S, Lewis BR, Isseh I, et al. Burden of hospitalization in clinically diagnosed peripheral artery disease: a community-based study. Vasc Med. 2018;23(1):23-31. https://doi.org/10.11 77/1358863X17736152.

4. Mahoney EM, Wang K, Keo HH, Duval S, Smolderen KG, Cohen DJ, et al. Vascular hospitalization rates and costs in patients with peripheral artery disease in the United States. Circ Cardiovasc Qual Outcomes. 2010;3(6):64251. https://doi.org/10.1161/CIRCOUTCOMES.109.930735.

5. Kullo IJ, Rooke TW. Peripheral artery disease. N Engl J Med. 2016;374:861-71 Massachusetts Medical Society.

6. Klinkert P, Post PN, Breslau PJ, van Bockel JH. Saphenous vein versus PTFE for above-knee femoropopliteal bypass. A review of the literature. Eur J Vasc Endovasc Surg. 2004;27(4):357-62. https://doi.org/10.1016/j.ejvs.2003.12.027.

7. Faries PL, Logerfo FW, Arora S, Hook S, Pulling MC, Akbari CM, et al. A comparative study of alternative conduits for lower extremity revascularization: all-autogenous conduit versus prosthetic grafts. J Vasc Surg. 2000;32(6):1080-90. https://doi.org/10.1067/mva.2000.111279.

8. Ambler GK, Twine CP. Graft type for femoro-popliteal bypass surgery. Cochrane Database Syst Rev. 2018;2:CD001487.

9. Chlupác J, Filová E, Bacáková L. Blood vessel replacement: 50 years of development and tissue engineering paradigms in vascular surgery. Physiol Res. 2009;58(Suppl 2):S119-39.

10. Bosma J, Turkçan K, Assink J, Wisselink W, Vahl AC. Long-term quality of life and mobility after prosthetic above-the-knee bypass surgery. Ann Vasc Surg 2012;26(2):225-32. https://doi.org/10.1016/j.avsg.2011.05.029.

11. Seifu DG, Purnama A, Mequanint K, Mantovani D. Small-diameter vascular tissue engineering. Nat Rev Cardiol. 2013;10(7):410-21. https://doi.org/10.103 8/nrcardio.2013.77.
12. L'Heureux N, Dusserre N, Marini A, Garrido S, de la Fuente L, McAllister T. Technology insight: the evolution of tissue-engineered vascular grafts--from research to clinical practice. Nat Clin Pract Cardiovasc Med. 2007:4:389-95 Nat Publ Group.

13. Natasha G, Tan A, Gundogan B, Farhatnia Y, Nayyer L, Mahdibeiraghdar S, et al. Tissue engineering vascular grafts a fortiori: looking back and going forward. Expert Opin Biol Ther. 2015;15:231-44.

14. Pashneh-Tala S, MacNeil S, Claeyssens F. The tissue-engineered vascular graft-past, present, and future. Tissue Eng Part B Rev. 2016;22(1):68-100. https://doi.org/10.1089/ten.teb.2015.0100.

15. Huang AH, Niklason LE. Engineering of arteries in vitro. Cell Mol Life Sci. 2014;71(11):2103-18. https://doi.org/10.1007/s00018-013-1546-3.

16. Roy S, Silacci P, Stergiopulos N. Biomechanical proprieties of decellularized porcine common carotid arteries. American journal of physiology-heart and circulatory physiology. Am Physiol Soc. 2005;289:H1567-76.

17. Gui L, Muto A, Chan SA, Breuer CK, Niklason LE. Development of decellularized human umbilical arteries as small-diameter vascular grafts. Tissue Eng Part A. 2009;15(9):2665-76. https://doi.org/10.1089/ten.tea.2008.0526.

18. Hillebrandt $\mathrm{KH}$, Everwien $\mathrm{H}$, Haep N, Keshi E, Pratschke J, Sauer IM. Strategies based on organ decellularization and recellularization. Transpl Int. 2019;32(6):571-85. https://doi.org/10.1111/tri.13462.

19. Colunga T, Dalton S. Building blood vessels with vascular progenitor cells. Trends Mol Med. 2018;24(7):630-41. https://doi.org/10.1016/j.molmed.2018.05.002.

20. Dahan N, Sarig U, Bronshtein T, Baruch L, Karram T, Hoffman A, et al. Dynamic autologous Reendothelialization of small-caliber arterial extracellular matrix: a preclinical large animal study. Tissue Eng Part A. 2017; 23(1-2):69-79. https://doi.org/10.1089/ten.tea.2016.0126.

21. Pineda DM, Dougherty MJ, Wismer MC, Carroll C, Tyagi S, Troutman DA, et al. Bovine carotid artery xenografts for hemodialysis access. J Vasc Surg. 2017;65(6):1729-34. https://doi.org/10.1016/j.jvs.2016.12.109.

22. Farber A, Major K, Wagner WH, Cohen JL, Cossman DV, Lauterbach SR, et al. Cryopreserved saphenous vein allografts in infrainguinal revascularization: analysis of 240 grafts. J Vasc Surg. 2003;38(1):15-21. https://doi.org/10.1016/ S0741-5214(03)00330-6.

23. Zilla P, Bezuidenhout D, Human P. Prosthetic vascular grafts: wrong models, wrong questions and no healing. Biomaterials. 2007;28(34):5009-27. https:// doi.org/10.1016/j.biomaterials.2007.07.017.

24. Casscells W. Migration of smooth muscle and endothelial cells. Critical events in restenosis. Circulation. 1992;86(3):723-9. https:/doi.org/10.1161/01.CIR.86.3.723.

25. Borschel GH, Huang Y-C, Calve S, Arruda EM, Lynch JB, Dow DE, et al. Tissue engineering of recellularized small-diameter vascular grafts. Tissue Eng. 2005;11(5-6):778-86. https://doi.org/10.1089/ten.2005.11.778.

26. Quint C, Kondo Y, Manson RJ, Lawson JH, Dardik A, Niklason LE. Decellularized tissue-engineered blood vessel as an arterial conduit. Proc Natl Acad Sci U S A. 2011;108(22):9214-9. https://doi.org/10.1073/pnas.1019506108.

27. Tiwari A, Salacinski HJ, Hamilton G, Seifalian AM. Tissue engineering of vascular bypass grafts: role of endothelial cell extraction. Eur J Vasc Endovasc Surg. 2001;21(3):193-201. https://doi.org/10.1053/ejvs.2001.1316.

28. Cho S-W, Lim SH, Kim I-K, Hong YS, Kim S-S, Yoo KJ, et al. Small-diameter blood vessels engineered with bone marrow-derived cells. Ann Surg. 2005; 241(3):506-15. https://doi.org/10.1097/01.sla.0000154268.12239.ed.

29. Melero-Martin JM, De Obaldia ME, Kang S-Y, Khan ZA, Yuan L, Oettgen $P$, et al. Engineering robust and functional vascular networks in vivo with human adult and cord blood-derived progenitor cells. Circ Res. 2008;103(2): 194-202. https://doi.org/10.1161/CIRCRESAHA.108.178590.

30. Melchiorri AJ, Bracaglia LG, Kimerer LK, Hibino N, Fisher JP. In vitro Endothelialization of biodegradable vascular grafts via endothelial progenitor cell seeding and maturation in a tubular perfusion system bioreactor. Tissue Eng Part C Methods. 2016;22(7):663-70. https://doi.org/10.1089/ten.tec.2015.0562.

31. Hofmann NA, Reinisch A, Strunk D. Isolation and large scale expansion of adult human endothelial colony forming progenitor cells. J Vis Exp. 2009; Available from:. https://doi.org/10.3791/1524.

32. Ensley AE, Nerem RM, Anderson DEJ, Hanson SR, Hinds MT. Fluid shear stress alters the hemostatic properties of endothelial outgrowth cells. Tissue Eng Part A. 2012;18(1-2):127-36. https://doi.org/10.1089/ten.tea.2010.0290.

33. Glynn JJ, Hinds MT. Endothelial outgrowth cells: function and performance in vascular grafts. Tissue Eng Part B Rev. 2014;20:294-303 online.liebertpub.com.

34. Peters EB. Endothelial progenitor cells for the vascularization of engineered tissues. Tissue Eng Part B Rev. 2018:24(1):1-24. https://doi.org/10.1089/ten. teb.2017.0127. 
35. Krawiec JT, Weinbaum JS, Liao H-T, Ramaswamy AK, Pezzone DJ, Josowitz $A D$, et al. In vivo functional evaluation of tissue-engineered vascular grafts fabricated using human adipose-derived stem cells from high cardiovascular risk populations. Tissue Eng Part A; 2016;22:765-775. Mary Ann Liebert, Inc, New Rochelle.

36. Maiti SK, Shivakumar MU, Mohan D, Kumar N, Singh KP. Mesenchymal stem cells of different origin-seeded bioceramic construct in regeneration of bone defect in rabbit. Tissue Eng Regen Med. 2018;15(4):477-92. https://doi. org/10.1007/s13770-018-0129-7.

37. Le Blanc K, Ringdén O. Immunomodulation by mesenchymal stem cells and clinical experience. J Intern Med; 2007;262:509-525 Wiley Online Library.

38. Wang K, Lin R-Z, Melero-Martin JM. Bioengineering human vascular networks: trends and directions in endothelial and perivascular cell sources. Cell Mol Life Sci. 2019;76(3):421-39. https://doi.org/10.1007/s00018-018-2939-0.

39. Au P, Daheron LM, Duda DG, Cohen KS, Tyrrell JA, Lanning RM, et al. Differentia in vivo potential of endothelial progenitor cells from human umbilical cord blood and adult peripheral blood to form functional long-lasting vessels. Blood. 2008; 111(3):1302-5. https://doi.org/10.1182/blood-2007-06-094318.

40. Fadini GP, Losordo D, Dimmeler S. Critical reevaluation of endothelial progenitor cell phenotypes for therapeutic and diagnostic use. Circ Res. 2012;110(4):624-37. https://doi.org/10.1161/CIRCRESAHA.111.243386.

41. Umemura T, Soga J, Hidaka T, Takemoto H, Nakamura S, Jitsuiki D, et al. Aging and hypertension are independent risk factors for reduced number of circulating endothelial progenitor cells. Am J Hypertens. 2008;21(11): 1203-9. https://doi.org/10.1038/ajh.2008.278.

42. Choi J-H, Kim KL, Huh W, Kim B, Byun J, Suh W, et al. Decreased number and impaired angiogenic function of endothelial progenitor cells in patients with chronic renal failure. Arterioscler Thromb Vasc biol. Am Heart Assoc. 2004;24:1246-52.

43. Ranjan AK, Kumar U, Hardikar AA, Poddar P, Nair PD, Hardikar AA. Human blood vessel-derived endothelial progenitors for endothelialization of small diameter vascular prosthesis. PLoS One. 2009;4(11):e7718. https://doi.org/1 0.1371/journal.pone.0007718.

44. Stroncek JD, Ren LC, Klitzman B, Reichert WM. Patient-derived endothelial progenitor cells improve vascular graft patency in a rodent model. Acta Biomater. 2012;8(1):201-8. https://doi.org/10.1016/j.actbio.2011.09.002.

45. Fernandez CE, Achneck HE, Reichert WM, Truskey GA. Biological and engineering design considerations for vascular tissue engineered blood vessels (TEBVs). Curr Opin Chem Eng. 2014;3:83-90. https://doi.org/10.1016/j. coche.2013.12.001.

46. Londono R, Badylak SF. Biomaterials from Decellularized tissues. In: Neves $\mathrm{NM}$, Reis RL, editors. Biomaterials from nature for advanced devices and therapies. Hoboken: Wiley; 2016. p. 190-210. https://doi.org/10.1002/978111 9126218.ch12

47. Mancuso L, Gualerzi A, Boschetti F, Loy F, Cao G. Decellularized ovine arteries as small-diameter vascular grafts. Biomed Mater. 2014;9(4):045011. https://doi.org/10.1088/1748-6041/9/4/045011.

48. Gratzer PF, Harrison RD, Woods T. Matrix alteration and not residual sodium dodecyl sulfate cytotoxicity affects the cellular repopulation of a decellularized matrix. Tissue Eng. 2006;12(10):2975-83. https://doi.org/10.1 089/ten.2006.12.2975.

49. Olausson M, Patil PB, Kuna VK, Chougule P, Hernandez N, Methe K, et al. Transplantation of an allogeneic vein bioengineered with autologous stem cells: a proof-of-concept study. Lancet. 2012;380(9838):230-7. https://doi. org/10.1016/S0140-6736(12)60633-3.

50. Faulk DM, Carruthers CA, Warner HJ, Kramer CR, Reing JE, Zhang L, et al. The effect of detergents on the basement membrane complex of a biologic scaffold material. Acta Biomater. 2014;10(1):183-93. https://doi.org/10.1016/ j.actbio.2013.09.006.

51. Crapo PM, Gilbert TW, Badylak SF. An overview of tissue and whole organ decellularization processes. Biomaterials. 2011;32(12):3233-43. https://doi. org/10.1016/j.biomaterials.2011.01.057.

52. Keane TJ, Swinehart IT, Badylak SF. Methods of tissue decellularization used for preparation of biologic scaffolds and in vivo relevance. Methods. 2015; 84:25-34. https://doi.org/10.1016/j.ymeth.2015.03.005.

53. Delgado LM, Pandit A, Zeugolis DI. Influence of sterilisation methods on collagen-based devices stability and properties. Expert Rev Med Devices. 2014;11(3):305-14. https://doi.org/10.1586/17434440.2014.900436.

54. Freytes DO, Badylak SF, Webster TJ, Geddes LA, Rundell AE. Biaxial strength of multilaminated extracellular matrix scaffolds. Biomaterials. 2004;25(12): 2353-61. https://doi.org/10.1016/j.biomaterials.2003.09.015.
55. Hodde JP, Record RD, Tullius RS, Badylak SF. Retention of endothelial cell adherence to porcine-derived extracellular matrix after disinfection and sterilization. Tissue Eng. 2002;8(2):225-34. https:/doi.org/10.1089/107632702753724996.

56. Matuska AM, McFetridge PS. The effect of terminal sterilization on structural and biophysical properties of a decellularized collagen-based scaffold; implications for stem cell adhesion. J Biomed Mater Res B Appl Biomater. 2015;103(2):397-406. https://doi.org/10.1002/jbm.b.33213.

57. Ouriel K. Peripheral arterial disease. Lancet. 2001;358(9289):1257-64. https:// doi.org/10.1016/S0140-6736(01)06351-6.

58. Wattanakit K, Folsom AR, Selvin E, Coresh J, Hirsch AT, Weatherley BD. Kidney function and risk of peripheral arterial disease: results from the atherosclerosis risk in communities (ARIC) study. J Am Soc Nephrol. 2007; 18(2):629-36. https://doi.org/10.1681/ASN.2005111204.

59. Pill K, Hofmann S, Redl H, Holnthoner W. Vascularization mediated by mesenchymal stem cells from bone marrow and adipose tissue: a comparison. Cell Regen (Lond). 2015;4:8.

60. Cunnane EM, Weinbaum JS, O'Brien FJ, Vorp DA. Future perspectives on the role of stem cells and extracellular vesicles in vascular tissue regeneration. Front Cardiovasc Med. 2018;5:86. https://doi.org/10.3389/fcvm.2018.00086.

61. Lee M, Jeong SY, Ha J, Kim M, Jin HJ, Kwon S-J, et al. Low immunogenicity of allogeneic human umbilical cord blood-derived mesenchymal stem cells in vitro and in vivo. Biochem Biophys Res Commun. 2014;446(4):983-9. https://doi.org/10.1016/j.bbrc.2014.03.051.

62. Reichert D, Friedrichs J, Ritter $\mathrm{S}$, Käubler T, Werner $\mathrm{C}$, Bornhäuser $\mathrm{M}$, et al. Phenotypic, Morphological and Adhesive Differences of Human Hematopoietic Progenitor Cells Cultured on Murine versus Human Mesenchymal Stromal Cells. Sci Rep. 2015;5:15680.

63. Steiner D, Köhn K, Beier JP, Stürzl M, Horch RE, Arkudas A. Cocultivation of Mesenchymal stem cells and endothelial progenitor cells reveals Antiapoptotic and Proangiogenic effects. Cells Tissues Organs. 2017;204(5-6): 218-27. https://doi.org/10.1159/000478654.

64. Fang J-F, Huang X-N, Han X-Y, Ouyang X, Fan L, Zhao X, et al. Combined transplantation of Mesenchymal stem cells and endothelial progenitor cells restores cavernous nerve injury-related erectile dysfunction. J Sex Med. 2018;15(3):284-95. https://doi.org/10.1016/j.jsxm.2018.01.005.

65. Stroncek JD, Grant BS, Brown MA, Povsic TJ, Truskey GA, Reichert WM. Comparison of endothelial cell phenotypic markers of late-outgrowth endothelial progenitor cells isolated from patients with coronary artery disease and healthy volunteers. Tissue Eng Part A. 2009;15(11):3473-86. https://doi.org/10.1089/ten.tea.2008.0673.

66. Rotmans JI, Heyligers JMM, Verhagen HJM, Velema E, Nagtegaal MM, de Kleijn DPV, et al. In vivo cell seeding with anti-CD34 antibodies successfully accelerates endothelialization but stimulates intimal hyperplasia in porcine arteriovenous expanded polytetrafluoroethylene grafts. Circulation. 2005; 112(1):12-8. https://doi.org/10.1161/CIRCULATIONAHA.104.504407.

67. Geelhoed WJ, Lalai RA, Sinnige JH, Jongeleen PJ, Storm C, Rotmans J. Indirect burst pressure measurements for the mechanical assessment of biological vessels. Tissue Eng Part C Methods. 2019;25(8):472-8. https://doi. org/10.1089/ten.tec.2019.0133.

68. Farndale RW, Buttle DJ, Barrett AJ. Improved quantitation and discrimination of sulphated glycosaminoglycans by use of dimethylmethylene blue. Biochim Biophys Acta. 1986;883(2):173-7. https://doi.org/10.1016/0304-4165(86)90306-5.

69. Vasa M, Fichtlscherer S, Adler K, Aicher A, Martin H, Zeiher AM, et al. Increase in circulating endothelial progenitor cells by statin therapy in patients with stable coronary artery disease. Circulation. 2001;103(24):288590. https://doi.org/10.1161/hc2401.092816.

70. Melero-Martin JM, Khan ZA, Picard A, Wu X, Paruchuri S, Bischoff J. In vivo vasculogenic potential of human blood-derived endothelial progenitor cells. Blood. 2007;109(11):4761-8. https://doi.org/10.1182/blood-2006-12-062471.

71. Soleimani M, Nadri S. A protocol for isolation and culture of mesenchymal stem cells from mouse bone marrow. Nat Protoc. 2009:4(1):102-6. https:// doi.org/10.1038/nprot.2008.221.

\section{Publisher's Note}

Springer Nature remains neutral with regard to jurisdictional claims in published maps and institutional affiliations. 